\title{
An Econometric Analysis Of Health Care Utilization In Kenya
}

\author{
Diana N. Kimani, PhD \\ Mercy G. Mugo, PhD \\ Urbanus M. Kioko, PhD
}

School of Economics, University of Nairobi

doi: 10.19044/esj.2016.v12n16p443 URL:http://dx.doi.org/10.19044/esj.2016.v12n16p443

\begin{abstract}
Background: Increasing access to health care has been a policy concern for many governments, Kenya included. The Kenyan government introduced and implemented a number of initiatives in a bid to address the healthcare utilization challenge. These initiatives include 10/20 policy, exemptions for user fees for some specific health services (treatment of children less than five years, maternity services in dispensaries and health centers, Tuberculosis treatment in public health facilities), and increase in the number of health facilities and health workforce. These initiatives notwithstanding, healthcare utilization in Kenya remains a challenge. The Kenya Household Health Expenditure and Utilization Survey of 2007 found that 17 percent of those who needed health care services could not access the services from both government and private health facilities largely due to financial constraints. This paper employed econometric analysis to examine what could be constraining health care utilization in Kenya despite all the efforts employed.
\end{abstract}

Methods: Using the 2007 Kenya Household Health Expenditures and Utilization Survey (KHHEUS) data $(n=8414)$, this paper investigates the factors that affect health care utilization in Kenya by estimating a count data negative binomial model. The model was also applied to public and private health facilities to better understand the specificities of poverty in these two facility types. Common estimation problems of endogeneity, heterogeneity, multicollinearity and heteroskedasticity are addressed.

Findings: The econometric analysis reveals that out-of-pocket expenditures, waiting time, distance, household size, income, chronic illness area of residence and working status of the household head are significant factors affecting health care utilization in Kenya. While income and distance are significant factors affecting public health care utilization they are not significant in explaining healthcare utilization in private facilities. In 
addition, working status of the household head, insurance cover and education are significant in explaining private and not public health care utilization. A striking finding is the positive relationship between distance and health care utilization implying that people will travel long distances to obtain treatment. This is perhaps associated with expectations of higher quality of care at far away higher level facilities, especially in rural areas.

Conclusion: The paper confirms the existing evidence of the negative effects of Out-of-Pocket (OOP) expenditures and other determinants of health care utilization. With a better understanding of why people use or do not use health services, health care organizations can seek to improve the quality of human life. The bypassing of health facilities for higher level far away facilities implies that it is not so much about availing health facilities, but the quality of the services offered in those facilities. The government should therefore assure quality to increase utilization of the lower level facilities, especially in the rural areas.

Keywords: Healthcare Utilization, Negative Binomial, Count Variables, Two Stage Residual Inclusion (2SRI), Kenya.

\section{Introduction}

The Kenyan government has over the years initiated a number of policy interventions with the aim of cushioning the citizens from high out-ofpocket expenditures and enhancing access to healthcare. These interventions include 10/20 policy, waiver and exemptions, reforms in National Hospital Insurance Fund (NHIF), Output-Based Aid (OBA) for reproductive health, Health Sector Services Fund (HSSF), and abolition of all fees for maternity services at public health facilities. Other initiatives include increasing the number of health facilities and the healthcare workforce.

These efforts notwithstanding, out-of-pocket expenditures remain high and access to health care is still a challenge to many households, especially the poor. Out-of-pocket payments for health care are a substantial share of total health care costs accounting for 54 percent in 2001/2002, 39.3 percent in 2005/2006, 36.7 percent in 2009/2010 and 39.8 in 2012/2013 (Government of Kenya, 2007; 2010c; Ministry of Health, 2015). The Kenya Household Health Expenditure and Utilization Survey of 2007 found that 17 percent of those who needed health care services could not access the services from both government and private health facilities.

Given the persistent challenge of healthcare access in Kenya, there is need for studies to analyze which factors significantly affect healthcare utilization in order to develop policies that will effectively tackle the challenge. Past studies on health care demand in Kenya have focused on specific health services such as maternal health services (Mungai, 2015; 
Machio, 2008), family planning (Okech et al., (2011) and outpatient services (Ellis and Mwabu, 2004) while others focus on examining the role of specific variables such as insurance (Gakii, 2013), poverty (Awiti, 2014), information (Muriithi 2013) and quality (Mwabu et al., 1993; Muriithi and Mwabu, 2014). Other studies have focused on rural areas (Ellis and Mwabu, 2004), urban slums (Muriithi, 2013; Okech et al., 2011). Besides, many of these studies model choice of health facility or treatment using multinomial logit, multinomial probit or nested logit model.

Health care utilization is generally assessed on volume basis such as number of hospitalizations per year or number of visits (Andersen and Newman 2005). In the literature, there are many studies which have carried out services utilization analyses with multivariate regression analyses based on the number of medical visits (Biro, 2009; Andersen and Newman 2005; Creel and Farrel, 2001; Lourenço, Ferreira and Barros, 2006). Majority of these studies make use of count data models.

Use of linear regression model on count outcomes can result in estimates which are biased and inefficient. There are situations, however, in which the linear regression model can provide reasonable results (especially when the dataset is large), but it is advisable to use models specifically designed for count outcomes. Creel and Farrel (2001), Long and Freese (2001) and Rutherford and Vasarhelyi (2006) provide an excellent review of the recent models for count data. The most commonly used models for count data regressions include one part modeling approaches (Poisson and negative binomial regression models); two part regression models (hurdle model); zero-inflated, and latent class models ${ }^{16}$.

One-part modeling approach uses a single distribution function, such as the Poisson or Negative Binomial (NB) distribution to analyze utilization of health services. They are considered as specifications based on Grossman's human capital model (Grossman, 1972, Wagstaff, 1986). In Grossman's framework, the individual is taken as the primary decision maker, fully controlling the choices regarding medical care.

The two-part model (TPM) visualizes health care demand within a principal-agent framework (Zweifel, 1981). Both the patient and the physician are assumed to be participants in a joint decision-making process (Rutherford and Vasarhelyi, 2006; Lourenço et al., 2006). The physician (agent) determines the frequency of treatment after the patient (the principal) has made the first contact. Hurdle models fall in this category but they are limited in the sense that they assume at most one illness spell (seek health services only once) during the recall period (Rutherford and Vasarhelyi, 2006; Lourenço et al., 2006).

\footnotetext{
${ }^{16}$ For an excellent review of these models, see Rutherford and Vasarhelyi (2006).
} 
This paper makes use of count data models since the dependent variable consists of discrete numbers of visits to the health facility. We envisage health care utilization within the Grossman's framework as opposed to the principal-agent's framework. This is based on the assumption that the household is the primary decision maker regarding health care utilization. In addition, patients in the survey on average one visit to the health facility implying that the physician had very little influence on the subsequent number of visits. Probably, this is because the recall period was only one month. Consequently, negative binomial model is the best suited compared to a Poisson regression model due to its restrictive assumption of equidispersion.

Our study makes several contributions to the literature. First, unlike previous studies, we model healthcare utilization using count data models bearing in mind that utilization is best measured by the number of visits as opposed to modeling health care provider or treatment choice. Second, we bring out the significant factors in healthcare utilization for the country as a whole, rural and urban, private and public health facilities and for both inpatient and outpatient. This is unlike other studies which just focus on one area. The paper is therefore very rich in information. Third, in estimating the determinants of healthcare utilization, we explicitly take into account the endogeneity of out-of-pocket expenditures and the large number of zero counts in the data set.

\section{Methodology and Data \\ 2.1 Analytical Framework}

A health care utilization model which motivates the empirical specification of this study is based on utility maximization. Borrowing from Biro (2009) and Mwabu (2007), individuals maximize their expected future lifetime utility, which depends on consumption (C) and health $(\mathrm{H})$. Since future health and survival probability are influenced by utilization of health care, the lifetime utility conditional on medical care can be written as:-

$$
\mathrm{U}=\mathrm{U}(\mathrm{C}, \mathrm{H})
$$

According to Grossman (1972), health depends on "investment" in health, which is a function of medical care and individual characteristics (like risky behaviour) that might influence the efficiency of health services.

$$
\mathrm{H}=\mathrm{f}\left(\mathrm{H}_{0}, \mathrm{M}\right)
$$

$\mathrm{H}$ is the health level after utilizing medical care, $\mathrm{H}_{0}$ is the initial health status (indicating pre-existing conditions), and $\mathrm{M}$ measures medical care utilization (e.g. number of visits to the doctor). The amount of money an individual spends on consumption medical services is constrained by income and wealth of the individual. Hence, the budget constraint is specified as:-

$$
\mathrm{PMM}_{\mathrm{MM}}+\mathrm{P}_{\mathrm{C}} \mathrm{C}=\mathrm{Y}
$$


Where $\mathrm{P}_{M}$ is the net (out-of-pocket) price of medical care and $\mathrm{P}_{C}$ is the price of other non-medical goods, when full income is expended on consumption and on medical care as well as on other health inputs needed to produce health. $\mathrm{Y}$ is exogenous income. Maximization of (2.1) subject to health production function (2.2) and budget constraint (2.3) can be characterized by the following Lagrangian function:-

$\lambda=U\left(C, f\left(H_{0}, M\right)\right)+\lambda\left(Y-P_{H} H-P_{C} C\right)$

From (2.4) the first order conditions for utility maximization after health has been produced in accordance with (2.2) can be expressed as:-

$$
\begin{aligned}
& \frac{\partial \lambda}{\partial C}=U_{C}-\lambda P_{C}=0 \\
& \frac{\partial \lambda}{\partial M}=U_{H} f_{M}-\lambda P_{M}=0 \\
& \frac{\partial \lambda}{\partial \lambda}=Y-P_{H} H-P_{C} C=0
\end{aligned}
$$

It is worth noting the following household's reduced-form demands for medical care $(\mathrm{M})$ and consumption of non-medical goods $(\mathrm{C})$.

$$
\begin{aligned}
& \mathrm{M}=\mathrm{M}\left(\mathrm{P}_{\mathrm{M}}, \mathrm{P}_{\mathrm{C}}, \mathrm{Y}, \mathrm{H}_{0}\right) \\
& \mathrm{C}=\mathrm{C}\left(\mathrm{P}_{\mathrm{M}}, \mathrm{P}_{\mathrm{C}}, \mathrm{Y}, \mathrm{H}_{0}\right)
\end{aligned}
$$

Following Mwabu (2007), solving equations 2.2, 2.6, and 2.7 simultaneously yields a hybrid health demand function of the form:$\mathrm{H}=\mathrm{H}\left(\mathrm{M}, \mathrm{Y}, \mathrm{P}_{\mathrm{M}}, \mathrm{P}_{\mathrm{C}}, \mathrm{H}_{0}\right)$

Consistent with demand theory, the entire set of prices for medical and consumption goods enters the demand function. All the arguments in 2.8 are as defined before as; $\mathrm{H}$ is health status after seeking medical care, $\mathrm{Y}$ is exogenous income, $\mathrm{H}_{0}$ is the initial health endowment or status and $\mathrm{P}_{M}$ and $\mathrm{P}_{\mathrm{C}}$ are the prices of medical care and consumption of non-medical goods, respectively. Following Mwabu (2007), equation 2.8 can be interpreted as a form of demand function for health where we maximize utility subject to budget constraint. The demand function is conditioned on exogenous income $\mathrm{Y}$, with other covariates in the function being treated as shift factors (shifting of demand curve due to changes in these variables). The cost of medical services depends on several factors such as type and quality of the service, and whether the individual has health insurance.. therefore, the price $\mathrm{P}_{M}$ is endogenous since it is the amount a household will spend on health care services conditional on choice of inputs (for example choosing a private hospital as opposed to a low cost government facility). In other words $\mathrm{P}_{\mathrm{M}}$ is not determined by the market forces of demand and supply but rather by the choices that households make. The price of $\mathrm{H}$ is endogenous and unobservable. It is determined household choices of health inputs and associated prices. (The endogeneity issue is discussed in greater detail in 
section 2.3.1). Since we are interpreting equation 2.8 as a demand function, $\mathrm{H}$ is optimal for a given number visits. Thus, assuming a one to one correspondence between visits and $\mathrm{H}$, it is possible to represent the dependent variable with the number of visits to the health facility (rather than by health status); henceforth denoted by V. No analytical loss is entailed by this assumption as long as $\mathrm{H}$ is optimal for a given level of $\mathrm{M}$. $\mathrm{Y}$ and all the other covariates will now be represented by $\mathrm{X}$, and $\mathrm{P}_{\mathrm{M}}$ will be represented by OOP (out-of-pocket expenditure per visit). Thus equation 2.8 can be proxied by:

$\mathrm{V}=\mathrm{V}(\mathrm{X}, \mathrm{OOP})$.

In particular, $\mathrm{X}$ includes household size, income (captured by total household expenditure), distance to the health facility, waiting time at the health facility, area of residence (rural/urban), presence of chronic illness, working status of the head of household, education level of the household head and insurance cover. Equation 2.9 is the main equation for estimation.

\subsection{Empirical Model \\ 2.3.1 Estimation Issues}

The estimation issues we deal with in this paper include endogeneity, heteroskedasticity, and heterogeneity. We test and address the endogeneity problem using Two-Stage Residual Inclusion (2SRI) which is discussed in section 2.3.2. Since count data is intrinsically heteroskedastic with variance increasing with the mean, we control for potential heteroskedasticity using robust estimates of the standard errors. By using negative binomial regression model (NBRM), the problem of unobserved heterogeneity is addressed.

For the NB distribution, the variance generally exceeds the mean, therefore better modelling health care utilization counts. The health care utilization model estimated is:-

$\mathrm{E}\left[\mathrm{V}_{\mathrm{i}} \mid \mathrm{X}_{\mathrm{i}}, \mathrm{OOP}_{\mathrm{i}}, \varepsilon_{1 \mathrm{i}}\right]=\exp \left(\mathrm{X}_{\mathrm{i}} \beta_{1}+\gamma_{1} \mathrm{OOP}_{\mathrm{i}}+\varepsilon_{1 \mathrm{i}}\right)$

Where index $\mathrm{i}$ refers to individual $\mathrm{i}$. $\mathrm{V}$ is the number of visits to the health facility, OOP is a unit out-of-pocket expenditure, and $\mathrm{X}$ is a vector of variables that might influence health care utilization. $\varepsilon_{1}$ is a latent heterogeneity term and it includes unobservables which influence health care utilization, but are independent from the regressors. These are basically such specific health characteristics which are not captured by the included health measures, such as being acquainted with a physician.

\subsubsection{Two-Stage Residual Inclusion (2SRI)}

The empirical model accounts for potential endogeneity of OOP expenditures, the large number of zero observations and heteroskedasticity. As a first step, we test for endogeneity of OOP expenditures using the two- 
stage residual inclusion estimation method (Terza, Basu and Rathouz, 2008) as used by Carpio, Wohlgenant and Boonsaeng, (2008) to deal with a continuous endogenous variable on a count model.

The 2SRI method is applicable when there are regressors in a nonlinear model that are correlated with unobserved (latent) variables, and these unobservables also influence the outcome variable. In the context of linear models, instrumental variable (IV) methods represent the established solution to the problem of endogeneity of regressors (Geraci, Fabbri and Monfardini, 2012). For example, the conventional Two-Stage Least Squares (2SLS) method is based on the assumption that the regression relationship of the outcome variable on the treatment variable and the observable confounders is linear. Applying 2SLS method can lead to bias in estimation when used with skewed outcomes such as the present case (Terza et al., 2008; Garrido et al., 2012). Angrist and Pischke (2009) call it "forbidden regression". They assert that forbidden regression crops up when researchers apply 2 SLS reasoning directly to nonlinear models.

The 2SRI method involves two stages. The first stage is a consistent estimation of the model for the endogenous regressor. The OOP health expenditures of individual $i$ is determined as:-

$\mathrm{OOP}_{\mathrm{i}}=\mathrm{Z}_{\mathrm{i} \alpha}+v_{\mathrm{i}}$

The variables included in vector $\mathrm{Z}$ include $\mathrm{X}$ which is a vector of exogenous variables in the health utilization model and instrumental variable while $v$ includes unobserved factors influencing OOP expenditures. Model 2.11 is estimated using OLS.

One difficulty in getting appropriate instruments to address the endogeneity problem is the fact that factors that affect OOP also affect access to health care services. However, in the literature, age categories have been used as instruments of health expenditure. Martin, Rice and Smith (2007) used proportion of households with lone pensioners (those aged 70 years and above and living alone) as an instrument for health expenditures. In Kenya, the proportion of population aged 65 years and above make up only 2.8 percent of the total population. This means that while the number of visits made by this age category may be insignificant compared to the whole population, the expenditures incurred by those few visits may be very significant. This is because this is the age category that more often than not suffers from chronic illnesses and requires inpatient services. In this sense therefore, this age category can make a good instrument for health expenditures because it is likely to be insignificant in explaining the number of visits to a health provider but significant in explaining OOP. This study used age categories 65 and above which we called senior.

The validity of the instrument (senior) is tested that (i) it must be correlated with OOP; and (ii) it must not be correlated with health care 
utilization except through OOP. Also the strength of the instrument is tested through F-test. For the case of a single endogenous regressor, Staiger and Stock (1997) recommend a critical value of greater than 10 in the first-stage $F$-statistic for instruments to be strong (Cameron and Trivedi, 2005; Stock and Yogo, 2002). For a single instrument and a single endogenous regressor as is the case here, this implies that the t-value for the instrument should be bigger than 3.2 or the corresponding p-value below 0.0016 (Schmidheiny, 2012).

On the issue of the instrumental variables being uncorrelated with the structural error term, we need to carry out identification tests. If the model is overidentified, in the sense that the instruments are more than the endogenous regressors, then we can test whether the instruments are uncorrelated with the error term. However, if the model is just identified, then there is no need to perform a test of overidentifying restrictions. Since this is a case of one endogenous variable and one instrument, then there is no need of identification test.

The second stage involves estimating the negative binomial model for the outcome variable, where both the residual from the first stage model and the endogenous explanatory variable are included as regressors. The rationale for including the residual from the first stage model is to serve as a control for unobservable variables that are correlated with the endogenous variable, thus allowing the endogenous variable to be treated as if it is an exogenous covariate during estimation (Mwabu, 2009). The model estimated in the second stage is:-

$\mathrm{E}\left[\mathrm{V}_{\mathrm{i}} \mid \mathrm{X}_{\mathrm{i}}, \mathrm{OOP}_{\mathrm{i}}, \hat{u}_{i}, \varepsilon_{2 \mathrm{i}}\right]=\exp \left(\mathrm{X}_{\mathrm{i}} \beta_{2}+\gamma_{2} \mathrm{OOP}_{\mathrm{i}}+\delta \hat{u}_{\mathrm{i}}+\varepsilon_{2 \mathrm{i}}\right)$

The notations follow that of equation (2.10). $\hat{\mathrm{u}}$ is the first stage residual. If OOP is exogenous in the health care utilization model, then $\delta$ should equal to zero. $\varepsilon_{2}$ includes unobservables which are independent from the included regressors. If OOP is exogenous, we estimate equation (2.10) using maximum likelihood estimation.

\subsection{Data and Definition of Variables}

\subsubsection{Data}

The study used data from the 2007 Household Health Expenditure and Utilization Survey (HHE\&US). The survey was conducted by the Kenya National Bureau of Statistics for the Ministry of Health in September and October 2007. The survey covered all provinces and districts of the country yielding a sample of 8,844 households (2,772 urban and 6,072 rural) and 38,317 individuals. Out of these, 6,514 individuals reported having been ill in the four weeks prior to the survey and 5,426 individuals utilized health services. 


\subsubsection{Variables}

Table 1 provides definitions and measurements of the variables used in estimations.

Table 1: Variable Definition, Measurement and Expected Effects

\begin{tabular}{|c|l|l|}
\hline Variables & Definitions and measurement & Expected Effects \\
\hline Visits & Number of visits made to the health care provider. & .. \\
\hline $\begin{array}{c}\text { Unit OOP } \\
\text { expenditure }\end{array}$ & $\begin{array}{l}\text { Costs of registration cards, consultation, drugs and } \\
\text { diagnosis in Kenya Shillings (Ksh). }\end{array}$ & Negative \\
\hline Distance & Distance in kilometers to the healthcare provider visited. & \multicolumn{1}{|c|}{ Negative } \\
\hline $\begin{array}{c}\text { Area of } \\
\text { residence }\end{array}$ & $\begin{array}{l}\text { Represents rural or urban; it is equal to 1 if one resides in } \\
\text { urban area; 0 otherwise }\end{array}$ & Positive \\
\hline Chronic illness & 1 if a member has a chronic illness; 0 otherwise & Positive \\
\hline Household size & The total number of members of the household. & Positive \\
\hline Waiting time & Time (hrs) between arrival and being seen by clinician. & Negative \\
\hline HH expenditure & Household expenditure per capita in Ksh. & Positive/negative \\
\hline Working status & 1 if head of household is working; 0 otherwise & Positive/negative \\
\hline Insurance cover & 1 if an individual has insurance cover; 0 otherwise & Positive \\
\hline Education level & 1 if HH head has secondary edu and above; 0 otherwise & Positive \\
\hline
\end{tabular}

\subsection{Results}

Table 2 presents sample statistics of the factors affecting health care utilization.

Table 2: Analytic Sample Characteristics

\begin{tabular}{|c|c|c|c|c|}
\hline \multirow[b]{2}{*}{ Variable } & \multirow[b]{2}{*}{ Mean } & \multirow{2}{*}{$\begin{array}{l}\text { Standard } \\
\text { Deviation }\end{array}$} & \multicolumn{2}{|c|}{ Range } \\
\hline & & & Minimum & Maximum \\
\hline $\begin{array}{lll}\begin{array}{l}\text { Education } \\
\text { above })\end{array} & (1=\text { secondary } & \text { and } \\
\end{array}$ & 0.27 & 0.44 & 0 & 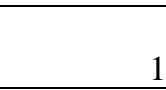 \\
\hline Visits (No.) & 1.37 & 0.73 & 0 & 8 \\
\hline $\begin{array}{l}\text { Distance to the facility visited } \\
(\mathrm{Km})\end{array}$ & 9.26 & 38.62 & 0 & 800 \\
\hline Household expenditure (Ksh) & 12,174 & 36,488 & 0 & $1,651,367$ \\
\hline $\begin{array}{l}\text { Chronic illness }(1=\text { chronically } \\
\text { ill) }\end{array}$ & 0.12 & 0.32 & 0 & 1 \\
\hline $\begin{array}{l}\text { Working status }(1=\text { HHhead } \\
\text { works })\end{array}$ & 0.19 & 0.39 & 0 & 1 \\
\hline Waiting time (Hours) & 0.92 & 1.86 & 0.02 & 45 \\
\hline Household size (No.) & 5.18 & 2.35 & 1 & 15 \\
\hline Residence (1 = urban) & 0.28 & 0.45 & 0 & 1 \\
\hline Insurance status ( $1=$ insured $)$ & 0.14 & 0.35 & 0 & 1 \\
\hline OOP expenditures per visit (Ksh) & 319 & 1,405 & 0 & 40,000 \\
\hline
\end{tabular}

Source: Author's computations, KHHEUS, 2007

Table 2 shows that, on average those who sought health care made one visit and spent an average of Ksh. 319 per visit as OOP expenditure. In addition, they had to wait for 55.2 minutes, on average, to receive care and had to travel a distance of $9.3 \mathrm{~km}$, on average, to seek care. The average 
household size of those who sought care was 5 members, and the average monthly expenditure per household was Ksh. 12,174. Of those who sought care, 72 percent were from rural areas, 12 percent had chronic illness, and 14 percent had some form of insurance cover. Twenty seven and 19 percent of those who sought care had household heads with education above secondary level and were working, respectively.

\subsection{Determinants of Health Care Utilization}

\subsubsection{Impact of out-of-pocket expenditure on health care utilization}

Test results for validity, strength and relevance of the instrument confirm that the instrument is highly correlated with the endogenous variable with a t-value of 3.44 and P-value of 0.000 , and is uncorrelated with the structural error term. Thus, senior is a valid and strong instrument (Appendix Table A1). Table 3 shows results from four models (2SRI and Negative Binomial Models for overall, public and private facilities' samples).

Table 0: Results of 2SRI and NB Regressions (Dependent Variable = Visits)

\begin{tabular}{|c|c|c|c|c|}
\hline Variable & 2SRI model & NB model & NB model & NB model \\
\hline Log of $\quad$ OOP & 0.015 & $-0.086 * * *$ & $-0.118 * * *$ & $-0.089 * * *$ \\
\hline Log of waiting time & $0.058 * *$ & $0.033 * * *$ & $0.041 * * *$ & $-0.079 * * *$ \\
\hline Log of distance & -0.016 & $0.037 * * *$ & $0.043 * * *$ & 0.009 \\
\hline Log of household & $0.129 * * *$ & $0.095 * * *$ & $0.069 * * *$ & $0.088^{*}$ \\
\hline Log of household & -0.008 & $0.023 * * *$ & $0.023 * *$ & 0.009 \\
\hline Insurance cover & -0.043 & -0.023 & 0.026 & $0.149 * * *$ \\
\hline Chronic illness & $0.083 * *$ & $0.108 * * *$ & $0.088 * * *$ & $0.127 * *$ \\
\hline Area of residence & -0.052 & $0.027 *$ & $0.059 * * *$ & $0.105 * *$ \\
\hline Working household & $-0.036 * *$ & $-0.044 * * *$ & -0.012 & $-0.102 * *$ \\
\hline Education & 0.003 & 0.022 & 0.007 & $0.115 * *$ \\
\hline OOP residual & -0.101 & & & \\
\hline Constant & 0.082 & $0.217 * * *$ & $0.350 * * *$ & $0.691 * * *$ \\
\hline Observations & 8049 & 8123 & 4241 & 962 \\
\hline
\end{tabular}

The results of the first model, 2SRI, show that OOP expenditure residual is -0.101 and not significant. This indicates that OOP expenditure is not endogenous; implying that negative binomial regression is the appropriate model. The discussion of the results is therefore based on NB models for overall, public and private.

The results show that OOP expenditures are significantly and negatively related to health care utilization in all the Negative Binomial models. This means that a 10 percent increase in the OOP expenditures decreases the difference in logs of expected counts in the number of visits by $0.86,1.18$, and 0.89 for public facilities and private facilities, respectively. Therefore OOP expenditures are a hindrance to health care utilization.

\footnotetext{
${ }^{17}$ Overall includes all health facilities (public, private, faith based etc)
} 
Income plays an important role in the demand for health care. Assuming that health is a normal good, demand for health is expected to increase with income. The results show that a ten percent increase in income leads to 0.23 increase in the difference in logs of expected counts in the number of visits to any health facility. Surprisingly, income is not a significant factor in seeking private health care, though it positively influences the number of visits.

Waiting time, though significant in explaining health care utilization, is positively related to the number of visits in the overall and public facilities. This suggests that while a consumer may consider the time spent in obtaining treatment as important, he or she may place a higher premium on the facility for other reasons. For instance, a patient may consider the time spent waiting for treatment as secondary to the quality of drugs and the attention received when he or she eventually gets treated. The positive relationship can also be interpreted to mean that long waiting time may cause a patient to go home untreated, hence be forced to make another visit to the health facility. Lack of options, especially in rural areas where public health facilities are few and far apart, may force patients to wait until they get treatment. On the other hand, waiting time significantly reduces the number of visits to private facilities. This could be explained by people having other options, especially in urban areas where most private facilities are located.

A person living in an urban area is more likely to seek treatment compared to the one in rural areas. This result is not surprising, since most of the health facilities in Kenya are located in urban areas, thus households residing in urban areas have more access to care than those living in rural areas. In addition, most urban residents (apart from those living in the slums) are likely to afford health care compared to those in rural areas.

Having a chronic illness is also a major determinant of health care utilization. A ten percent increase in chronic illnesses leads to 1.1 percent increase in the number of visits to all health facilities, 0.9 percent to public facilities and 1.3 percent to private facilities. This can be explained by the fact that most chronic illnesses require routine management, thereby occasioning more frequent visits to health facilities.

The larger the household size, the more the number of visits to a health facility. In particular, a ten percent increase in household size leads to 0.95 increase in the difference in logs of expected counts in the number of visits to all health facilities, 0.69 to public and 0.88 percent to private facilities. The implication is that in large households there is higher probability of falling sick especially contagious illnesses, thus a higher likelihood of making many visits to a health facility.

Contrary to theoretical and empirical expectations, our findings show that the longer the distance to the health facility, the higher the levels of 
utilization, implying that people will travel long distances to obtain treatment. This is perhaps associated with expectations of higher quality of care at far away higher level facilities, especially in rural areas. Though this would apply especially to private facilities which are perceived to offer higher quality services than public facilities, distance is not a significant factor in seeking private health care.

Education level significantly increases private health care utilization. Household heads with secondary education and above are more likely to utilize private facilities than those with primary level and below. This result is not surprising since those who are more educated are likely to have better jobs, hence can afford to utilize health care at private facilities. In addition, educated people are likely to understand and appreciate the benefits of health care, hence demand it.

Working status significantly reduces health care utilization. Though not expected, the negative coefficient of this variable could be applicable in the Kenyan situation given that a majority of those working are in the informal sector. This means that any visit to a health facility, either by them or their children, implies lost earnings for that period. Hence, those who are working may choose to forego visits to health facilities unless it is extremely important to do so. This finding could also be explained by the fact that those who work, especially in formal sectors, are also more educated, invest more in their health and nutrition, and therefore, do not require to utilize health services that often since they are healthy.

The results show that health insurance cover is an important determinant for utilizing private health care, but not in public and all facilities models. According to the results, a ten percent increase in insurance coverage leads to 1.5 percent increase in the difference in logs of expected counts in the number of visits to private health facilities. This finding is not surprising since most of those who seek care from private facilities either have individual or employer based private insurance.

\subsubsection{Discussion of Results}

This paper sought to analyze of the determinants of health service utilization. The results show that OOP expenditures negatively affect health care utilization in all facilities, both private and public. Other studies with similar findings include Mwabu, Ainsworth and Nyamete, 1993; Gertler, Locay and Sanderson, 1987; Ntembe, 2009; Canaviri, 2007; Ssewanyana et al., 2006; Mendola, Bradenkamp and Gragnolati, 2007. However, Lavy and Quigley (1993) show that although statistically significant, costs of medical services are less important in terms of their effect on the choice of treatment. In an earlier study by Heller (1982), cash price did not prove to be a factor 
differentiating users from non-users of medical care, whether outpatient or inpatient.

Our results show that people will travel long distances to obtain treatment. This finding is similar to a study in India which found that women would travel long distances to obtain private care, perceived to offer better quality than public services (Bhatia, 2001). In Bangladesh (Ensor et al., 2001) and Burkina Faso (Develay, Sauerborn and Diesfeld, 1996), it was found that people residing close to cities are often willing to bypass local facilities, traveling to higher level facilities in urban areas perceived to offer better quality. However, studies by Ichoku and Leibbrandt (2003); Ssewanyana et al. (2006) and Ntembe (2009) found a negative impact of distance on health care demand. Distance is also cited as a reason women choose to deliver at home rather than at a health facility (Akin and Hutchinson, 1999; Amooti-Kaguna and Nuwaha, 2000; and Raghupathy, 1996).

Of interest also is the positive relationship between education of the household head and utilization of health services. This undoubtedly is a beneficial thing for population health status. It may be that education is acting as a proxy for lifetime income or wealth, and reflecting a positive effect of this on health care utilization. Other empirical studies such as Ssewanyana et al. (2006) and Cisse (2011) found that the higher the level of education, the higher the probability of seeking modern health care. Kosimbei (2005) found mother's level of education to be an important determinant of child health care utilization.

People residing in urban areas utilize health care more than those in rural areas since most of these facilities are located in urban areas. The World Bank Report (1993) for example, reported that households living in urban areas seek and obtain health care services more often than their counterparts in rural areas. This is very evident in Kenya since the public levels 4, 5 and referral hospitals are all located in the main urban areas. In addition, private hospitals are also in urban areas, where they can attract more clients.

Similar to our findings, a number of studies (Cisse, 2011; Ntembe, 2009; Ssewanyana et al., 2006; Ichoku and Leibbrandt, 2003) found income to be positive and a significant determinant of demand for health care. However, some studies found income not to have a significant effect on health seeking behavior. Heller (1982), for example, found that income only had a minor impact on whether or not the household seeks medical care. The study also indicated that unlike most other developing countries, income is not a barrier to access to medical care in Malaysia. Lindelow (2003) found that income was not an important determinant of health care choices in Mozambique. 
Insurance cover is also a significant factor in explaining private health care utilization in Kenya. Similar findings include Jowett, Deolalikar and Martinsson (2004) and Ekman (2007). In Vietnam, Jowett et al. (2004) examined the effects of voluntary health insurance on the choice of provider and type of care. They found that poorer insured persons tend to use inpatient care more compared with poorer uninsured individuals, a difference that is not found at higher income levels. Ekman (2007) found evidence that insurance increased the intensity of utilization and reduced OOP spending in Jordan.

\subsection{Conclusion and Policy Recommendations}

This paper has generated policy relevant results. The findings confirm the existing evidence of the negative effects of OOP expenditures and other determinants of health care utilization. With a better understanding of why people use or do not use health services, health care organizations can seek to improve the quality of human life. The paper also contributes to the debate on relative importance of access versus quality of care. It has illustrated that quality of health care is given more weight to the extent that people are willing to wait long hours and travel long distances to access quality care. Policy makers in Kenya should therefore spend more resources in improving quality of care in existing facilities.

What emerges clearly from this paper is that OOP expenditures are not an appropriate financing mechanism for health services in Kenya, and reliance on them needs to be reduced. However, the main question is; what should replace them? Gilson and McIntyre (2005) argue that the removal of fees should not be thought of as a simple exercise that can be implemented at the stroke of a pen. It requires alternative funding mechanisms (tax-based financing, social health insurance, subsidized community-based health insurance, private insurance, vouchers, conditional cash transfers, and equity funds) to be in place. However, the decisions on the choice of one or mixture of mechanisms to implement needs to be evidence-based and should be aimed at reducing reliance on OOP funding for health services. These alternative funding mechanisms have their own challenges and should be evaluated one at a time. The government should therefore evaluate other funding mechanisms which can be put in place to reduce reliance on OOP

Removing financial barrier to health care utilization is not the only solution. This paper shows that there are other significant determinants of health care utilization such as distance, waiting time, household size, income, chronic illness, area of residence, and working status of the household head. For private health care utilization, having an insurance cover and an educated household head are also significant determinants. Therefore, reforms implemented should address both financial and non-financial barriers to 
health care utilization. Bypassing of facilities implies that access is not only about the proximity of health facilities, but also the quality of health services. The government should therefore aim at equipping the lower level facilities with drugs, staff and equipment to reduce or address bypassing of these facilities for higher level facilities in faraway places.

\section{References:}

Akin, J. S., \& Hutchinson, P. (1999). Health Care Facility Choice and the Phenomenon of Bypassing. Health Policy and Planning 14(2): 135-151.

Amooti-Kaguna, B., \& Nuwaha, F. (2000). Factors Influencing Choice of Delivery Sites in Rakai District of Uganda. Social Science and Medicine 50: 203-213.

Andersen, R.M., \& Newman, J. F. (2005). Societal and Individual Determinants of Medical Care Utilization in the United States. The Milbank Quarterly, Vol. 83 (4):1-28.

Angrist, J. D., \& Pischke, J. S. (2009). Mostly Harmless Econometrics. An Empiricist's Companion. Princeton and Oxford. Princeton University Press. Awiti, J. (2014). Poverty and Healthcare Demand in Kenya. BMC Health Services Research 14:560

Bhatia, J. C. (2001). Health Care Seeking and Expenditure by Young Indian Mothers in the Public and Private Sectors. Health Policy and Planning 16(1): 55-61.

Bíró, A. (2009). Health Care Utilization of Older People in Europe - Does Financing Structure Matter? Central European University.

Cameron, A. C., and Trivedi P. K. (2005). Supplement to Microeconometrics: Methods and Applications. New York: Cambridge University Press.

Cameron, A, Trivedi, P., Milne, F., \& Piggott, J. (1988). A Microeconometric Model of the Demand for Health-Care and HealthInsurance in Australia. Review of Economic Studies (55), 85-106

Canaviri, L. J. A. (2007). A Random Parameter Logit Model for Modeling Health Care Provider Choice in Bolivia. Paper No. 3263. Munich Personal RePEc Archive (MPRA).

Carpio, C. E., Wohlgenant, M. K., \& Boonsaeng, T. (2008). The Demand for Agritourism in the United States. Journal of Agricultural and Resource Economics. 33(2): 254-269.

Cisse, A. (2011). Analysis of Health Care Utilization in Côte d'Ivoire. Nairobi: African Economic Research Consortium (AERC).

Creel, M., \& Farrell, M. (2001). Likelihood Demand Approaches to Modeling Demand for Medical Care. Working Paper 498-01.Universitat Autonoma de Barcelona. 
Develay, A., Sauerborn, R., \& Diesfeld, H. J. (1996). "Utilization of Health Care in an African Urban Area: Results From a Household Survey in Ouagadougou, Burkino-Faso." Social Science and Medicine 43(11): 16111619.

Ellis R. P. \& Mwabu G. M. (2004). The Demand for Outpatient Medical Care in Rural Areas. https://www.bu.edu/econ/files/2012/11/dp140ellis.pdf Ekman, B. (2007). The Impact of Health Insurance on Outpatient Utilization and Expenditure: Evidence from One Middle-Income Country Using National Household Survey Data. Health Research Policy and Systems 5:6 doi:10.1186/1478-4505-5-6. BioMed Central Ltd.

Ensor, T., Hossain, A., Ali, Q. L., Begum, S. A., \& Moral, A.H. (2001). Geographic Resource Allocation of the Public Health Budget in Bangladesh. Research Paper 21. Health Economics Unit, Ministry of Health and Family Welfare.

Gakii, J. (2013). Demand for Health Care in Kenya: The Effect of Health Insurance. KIPPRA Discussion Paper No. 155.

Garrido, M. M., Deb, P., Burgess, J. F., \& Penrod, J. D. (2012). Choosing Models for Health Care Cost Analyses: Issues of Nonlinearity and Endogeneity. Health Services Research 47(6) 2377-2397.

Geraci, A., Fabbri, D., \& Monfardini, C. (2012). "Testing Exogeneity of Multinomial Regressors in Count Data Models: Does Two Stage Residual Inclusion Work?," Working Papers 14/03. Health, Econometrics and Data Group (HEDG)., University of York.

Gertler, P., Locay, L., \& Sanderson, W. (1987). Are User Fees Regressive? The welfare Implications of Health Care Financing Proposals in Peru. National Bureau of Economic Research

Gilson, L., \& McIntyre, D. (2005). Removing User Fees for Primary Care in Africa: The Need for Careful Action. British Medical Journal 331:762-5. Government of Kenya. (2009). Kenya Household Health Expenditure and Utilization Survey Report 2007. Ministry of Medical Services and Ministry of Public Health and Sanitation.

Grossman, M. (2004). The Demand for Health, 30 Years Later: A Very Personal Retrospective. The Journal of Health Economics, 23:629-636.

Grossman, M. (1999). The Human Capital Model of the Demand for Health. Working Paper 7078. National Bureau of Economic Research.

Grossman, M. (1972). On the Concept of Health Capital and the Demand for Health. The Journal of Political Economy, 80:223-255.

Havemann, R., \& van der Berg, S. (2002). The Demand for Health Care in South Africa. Stellenbosch Economic Working Papers.

Heller, P. S. (1982). "A Model of the Demand for Health Services in Peninsular Malaysia", Social Science and Medicine, 16: 267-84. 
Ichoku, H. E., \& Leibbrandt, M. (2003). Demand for Health Care Services in Nigeria: A Multivariate Nested Logit Model. African Development Bank.

Jowett, M., Deolalikar, A., \& Martinsson, P. (2004). Health Insurance and Treatment Seeking Behaviour: Evidence from a Low-Income Country. Health Economics, 13:845-857.

Kosimbei, G. (2005). Child Health Care Seeking Behaviour in Kenya. Discussion Paper No. 50. Nairobi: Kenya Institute for Public Policy Research and Analysis.

Lahiri, K., \& Xing, G. (2001). An Econometric Analysis of Veterans' Health Care Utilization using Two-Part Models. Department of Economics, State University of New York, Albany.

Lavy, V., \& Quigley, M. J. (1993). Willingness to Pay for Quality and Intensity of Medical Care: Evidence from Low Income Households in Ghana". Working Paper No. 94. Living Standards Measurement Study, Washington DC: World Bank.

Long, J. S., \& Freese, J. (2001). Regression Models for Categorical Dependent Variables Using Stata. Stata Corporation. Texas: College Station. Lourenço, Ó. D., Ferreira, P. L., \& Barros P. P. (2006). Econometric Analysis of Healthcare Utilization. An Alternative Hurdle Specification Using Latent Class Models. Fifteenth European Workshop on Econometrics and Health Economics 6(9) 1-35.

Machio, P. (2008). Demand for Maternal Health Care Services in Kenya. Unpublished MA Thesis, University of Nairobi.

Martin, S., Rice, N., \& Smith, P. C. (2007). Does Health Care Spending Improve Health Outcomes? Evidence from English Programme Budgeting Data. Journal of Health Economics 27 826-842. ScienceDirect.

Mendola, M., Bredenkamp, C., \& Gragnolati, M. (2007). The Impoverishing Effect of Adverse Health Events: Evidence from the Western Balkans. World Bank Policy Research Working Paper Series.

Ministry of Health, (2015). Kenya National Health Accounts 2012/13. Nairobi: Ministry of Health.

Mungai, S. (2015). Determinants of Maternal Health Care Services in Kenya. Unpublished MA Thesis. University of Nairobi, Kenya.

Muriithi, M. \& Mwabu, G. (2014). Demand for Health Care in Kenya: The Effects of Information about Quality. IGI Global. Pennsylvania, United States.

Muriithi, M. K. (2013). The Determinants of Health-Seeking Behavior in a Nairobi Slum, Kenya. European Scientific Journal vol.9, No.8

Mwabu, G. (2009). The Production of Child Health in Kenya: A Structural Model of Birth Weight. Journal of African Economies 18 (2), 212 - 260.

Mwabu, G. (2007). Health Economics for Low-Income Countries. Center Discussion Paper No. 955. Economic Growth Center, Yale University. 
Mwabu, G., Ainsworth, M., \& Nyamete, A. (1993). Quality of Medical Care and Choice of Medical Treatment in Kenya: An Empirical Analysis. The Journal of Human Resources, Vol. 28, No. 4, Special Issue: Symposium on Investments in Women's Human Capital and Development pp. 838-862. University of Wisconsin Press. http://www.jstor.org/stable/146295 . Ntembe, A. N. (2009). User Charges and Health Care Provider Choice in Cameroon. International Review of Business Research Papers Vol. 5 No. 6, Pp.33-49

Okech, T. C., Wawire, N. W., \& Mburu T. K. (2011). Empirical Analysis of Determinants of Demand for Family Planning Services in Kenya's City Slums. Global Journal of Health Science Vol. 3 No. 2.

Raghupathy, S. (1996). Education and the Use of Maternal Health Care in Thailand." Social Science and Medicine 43(4): 459-471.

Rutherford, A. R., \& Vasarhelyi, K. (2006). Modeling the Demand for Health Care. Complex Systems Modeling Group. The IRMACS Centre, Simon Fraser University.

Schmidheiny, K. (2012). Short Guides to Microeconometrics. Universitat Basel.

Ssewanyana, S., Nabyonga, O. J., Kasirye, I., \& Lawson, D. (2006). Demand for Health Care Services in Uganda: Implications for Poverty Reduction. Munich Personal RePEc Archive

Staiger, D., \& Stock, J. H. (1997). Instrumental Variables Regression with Weak Instruments. Econometrica, 65, 557 - 586.

Stock, J. H., \& Yogo, M. (2002). Testing for Weak Instruments in Linear IV Regression. Technical Working Paper 284. National Bureau of Economic Research. 1050 Massachusetts Avenue, Cambridge, MA 02138. http://www.nber.org/papers/T0284

Terza, J. V., Basu, A., \& Rathouz, P. J. (2008). Two-Stage Residual Inclusion Estimation: Addressing Endogeneity in Health Econometric Modeling. Journal of Health Economics, 27: 531-543.

Wagstaff, A. (1986). The Demand for Health - Some New EmpiricalEvidence. Journal of Health Economics. (5) 195-233.

World Bank, (1993). World Development Report 1993: Investing in Health. New York: Oxford University Press.

Zweifel, P. (1981). Supplier-Induced Demand in a Model of Physician Behaviour. Health Economics 245-267. North-Holland, Amsterdam. 


\section{APPENDIX}

Table A1: Testing the Validity of Instrument for Out-of-Pocket Health Expenditure

\begin{tabular}{|c|c|c|c|c|}
\hline \multirow[b]{2}{*}{ Variable } & \multicolumn{2}{|c|}{ Log of OOP expenditures model } & \multicolumn{2}{|c|}{ Visits model } \\
\hline & Coefficient & $\mathbf{t}$ & Coefficient & $\mathbf{Z}$ \\
\hline Log of OOP expenditures & & & $-0.086 * * *$ & -18.84 \\
\hline Log of waiting time & $-0.254 * * *$ & -9.31 & $0.033 * * *$ & 3.83 \\
\hline Log of distance & $0.516 * * *$ & 28.18 & $0.036 * * *$ & 5.64 \\
\hline Log of household size & $-0.294 * * *$ & -6.35 & $0.100 * * *$ & 5.88 \\
\hline Log of expenditure & $0.299 * * *$ & 13.09 & $0.022 * * *$ & 2.86 \\
\hline Insurance cover & $0.227 * * *$ & 4.58 & -0.020 & -1.14 \\
\hline Chronic illness & $0.245 * * *$ & 4.29 & $0.107 * * *$ & 4.95 \\
\hline Area of residence & $0.775 * * *$ & 18.15 & $0.026^{*}$ & 1.67 \\
\hline Working household head & $-0.076^{*}$ & -1.87 & $-0.043 * * *$ & -2.87 \\
\hline Education & $0.204 * * *$ & 5.21 & 0.023 & 1.53 \\
\hline Senior & $0.344 * * *$ & 3.44 & 0.035 & 1.02 \\
\hline Constant & $1.292 * * *$ & 6.55 & $0.212 * * *$ & 3.14 \\
\hline $\begin{array}{l}\text { Observations } \\
\text { P-Value } \\
\text { R-Squared } \\
\text { F-statistic }(10,8038) \\
\text { Wald chi2(11) }\end{array}$ & \multicolumn{2}{|l|}{$\begin{array}{l}8049 \\
0.0000 \\
0.2424 \\
203.92\end{array}$} & \multicolumn{2}{|l|}{$\begin{array}{l}8049 \\
0.0000\end{array}$} \\
\hline
\end{tabular}

*Significant at 10 percent $* *$ Significant at 5 percent $* * *$ Significant at 1 percent 